\title{
Electrical breakdown phenomena of dielectric elastomers
}

\author{
Mateiu, Ramona Valentina; Yu, Liyun; Skov, Anne Ladegaard
}

Published in:

Proceedings of SPIE - The International Society for Optical Engineering

Link to article, DOI:

$10.1117 / 12.2258719$

Publication date:

2017

Document Version

Publisher's PDF, also known as Version of record

Link back to DTU Orbit

Citation (APA):

Mateiu, R. V., Yu, L., \& Skov, A. L. (2017). Electrical breakdown phenomena of dielectric elastomers.

Proceedings of SPIE - The International Society for Optical Engineering, 10163, [1016328].

https://doi.org/10.1117/12.2258719

\section{General rights}

Copyright and moral rights for the publications made accessible in the public portal are retained by the authors and/or other copyright owners and it is a condition of accessing publications that users recognise and abide by the legal requirements associated with these rights.

- Users may download and print one copy of any publication from the public portal for the purpose of private study or research.

- You may not further distribute the material or use it for any profit-making activity or commercial gain

- You may freely distribute the URL identifying the publication in the public portal

If you believe that this document breaches copyright please contact us providing details, and we will remove access to the work immediately and investigate your claim 


\title{
Electrical breakdown phenomena of dielectric elastomers
}

\author{
Ramona V. Mateiu ${ }^{\mathrm{a}}$, Liyun $\mathrm{Yu}^{\mathrm{b}}$, Anne L. Skov*b \\ ${ }^{a}$ Center for Electron Nanoscopy, Technical University of Denmark, Fysikvej 307, 2800 Kgs. \\ Lyngby, Denmark; ${ }^{\mathrm{b}}$ Danish Polymer Centre, Department of Chemical and Biochemical Engineering, \\ Technical University of Denmark, Søltofts Plads 227, 2800 Kgs. Lyngby, Denmark
}

\begin{abstract}
Silicone elastomers have been heavily investigated as candidates for dielectric elastomers and are as such almost ideal candidates with their inherent softness and compliance but they suffer from low dielectric permittivity. This shortcoming has been sought optimized by many means during recent years. However, optimization with respect to the dielectric permittivity solely may lead to other problematic phenomena such as premature electrical breakdown. In this work, we investigate the electrical breakdown phenomena of various types of permittivity-enhanced silicone elastomers. Two types of silicone elastomers are investigated and different types of breakdown are discussed. Furthermore the use of voltage stabilizers in silicone-based dielectric elastomers is investigated and discussed.
\end{abstract}

Keywords: Silicone elastomers, dielectric, electrical breakdown, voltage stabilization, characterization.

\section{INTRODUCTION}

Silicone elastomers are gaining more and more attention as dielectric elastomer candidates, mainly due to the inherent reliability arising from the covalently crosslinked silicone, which stands in contrast to the commonly used acrylic adhesive by $3 \mathrm{M}$, namely VHB. VHB has proven to be an excellent material to showcase the possibilities of dielectric elastomers e.g. extreme extensibilities ${ }^{1,2}$ but it does not possess reliability upon use as is required for the material to become a commercial dielectric elastomer transducer ${ }^{3,4}$. Silicone elastomers, on the other hand, suffer from low dielectric permittivity compared to acrylics and polyurethane based elastomers ${ }^{5}$. Many approaches to increase dielectric permittivity of silicone elastomers exist, including amongst others mixing in metal oxides ${ }^{6-8}$ or high permittivity liquids ${ }^{9,10}$, covalent grafting of dipoles ${ }^{11-14}$ and use of copolymers ${ }^{15,16}$. For more details on these methods see the review on silicone elastomers utilized as dielectric elastomers by Madsen et $\mathrm{al}^{17}$. Most dielectric enhancement methods introduce a reduction in the electrical breakdown strength and therefore the elastomers from such methods will need to be operated at a lower voltage for reliability. This is unfavorable but at the current stage of dielectric elastomer development the electrical breakdown processes are not fully understood ${ }^{18,19}$. So as such there exists no guideline on how to formulate elastomers with high electrical breakdown strength except the generic guidelines on what to avoid such as percolation of fillers etc ${ }^{20,21}$.

So-called voltage stabilization of high voltage cable insulation materials has been heavily investigated but with the main focus on thermoplastic or lightly crosslinked polyethylene (PE). The principle relies on the addition of low-molecular weight aromatic substances to the PE matrix and the electrical breakdown strength of the insulating material has been shown to be increased with almost $50 \%{ }^{22-24}$. However, for silicone elastomers such substances are not miscible in the silicone matrix and thus molecular grafting of the additives is required in order for reliable and reproducible elastomer films to be made. Most formulations of silicone elastomers with non-grafted low-molecular weight aromatic substances (i.e. additives) cause an easy detectable macroscopic phase separation with purely aromatic regions and thus local loss of insulating properties. Therefore the complexity of voltage stabilization of silicone elastomers increases. First of all chemical approaches to allow for incorporation of the additive onto the silicone elastomer backbone is required and finally the structure must be tailored in such way that microscopic phase separation favors voltage stabilization ${ }^{16}$ rather than electrical conduction.

Recent studies have shown that by incorporation of e.g. dipolar moieties in minute amounts the electrical breakdown strength can be increased. Such studies include incorporation of aromatics ${ }^{16}$ and chloro propyl groups ${ }^{25,26}$ on the silicone backbone. In this study we focus on the chloro propyl functionalized silicone elastomers prepared in Madsen et $\mathrm{al}^{25}$ and investigate the electrical breakdown patterns of two similar chloro propyl functionalized silicone elastomers which break

Electroactive Polymer Actuators and Devices (EAPAD) 2017, edited by Yoseph Bar-Cohen, Proc. of SPIE Vol. 10163, 1016328 · @ 2017 SPIE · CCC code: 0277-786X/17/\$18 · doi: 10.1117/12.2258719 
down electrically in a rather different way as well as we compare them to a silicone based reference. Thermogravimetric analysis (TGA) and scanning electron microscopy (SEM) are used to evaluate the elastomers before and after electrical breakdown. Furthermore the TGA potentially provides a basis for evaluation of the energies involved in the electrical breakdown process.

\section{EXPERIMENTAL SECTION}

\subsection{Materials}

Vinyl-terminated PDMS, DMS-V31 $\left(\bar{M}_{w} \approx 28000 \mathrm{~g} \mathrm{~mol}^{-1}\right)$, and a hydride-functional cross-linker, HMS-301, were acquired from Gelest Inc. The platinum cyclovinylmethyl siloxane complex catalyst (511) was purchased from Hanse Chemie, while silicon dioxide amorphous hexamethyldisilazane-treated particles (SIS6962.0) were purchased from Fluorochem. The inhibitor Pt88 was acquired from Wacker Chemie AG, and all other chemicals were acquired from Sigma-Aldrich and used as received, unless otherwise stated.

Two types of copolymers (Co-1 and Co-2) with two different spacer lengths between the alkyl chloride-groups were synthesized according to previous work ${ }^{25}$.

\subsection{Film preparation}

Co-1, Co-2, or DMS-V31 and an 8-functional cross-linker HMS-301 were mixed with treated silica particles (25 wt $\%$ ) and inhibitor (1 wt\%, Pt88) and then treated on a FlackTek Inc. DAC 150.1 FVZ-K SpeedMixer ${ }^{\mathrm{TM}}$. The catalyst (511) $(1.5 \mathrm{ppm})$ was added thereafter and the mixture was speed-mixed once more. The uniform mixtures thus made were coated on a glass substrate using a film applicator (3540 bird, Elcometer, Germany) with $150 \mu \mathrm{m}$ blade. Films were fully cured in the oven for $1 \mathrm{~h}$ at $115^{\circ} \mathrm{C}$.

\subsection{Electrical breakdown strength determination}

Electrical breakdown tests were performed on an in-house-built device based on international standards (IEC 60243-1 (1998) and IEC 60243-2 (2001)), while film thicknesses were measured through the microscopy of cross-sectional cuts, and the distance between the spherical electrodes was set accordingly with a micrometer stage and gauge. An indent of less than $5 \%$ of sample thickness was added, to ensure that the spheres were in contact with the sample. The polymer film was slid between the two spherical electrodes (diameter of $20 \mathrm{~mm}$ ), and the breakdown was measured at the point of contact by applying a stepwise increasing voltage (50-100 V step $\left.{ }^{-1}\right)$ at a rate of $0.5-1$ steps $\mathrm{s}^{-1}$. Each sample was subjected to 12 breakdown measurements, and an average of these values was given as the breakdown strength of the sample.

\subsection{Thermogravimetric analysis (TGA)}

Thermogravimetric analysis (TGA) was performed on a Discovery TGA from TA Instruments in a nitrogen atmosphere with a heating rate of $10{ }^{\circ} \mathrm{C} \mathrm{min}^{-1}$ from RT to $900{ }^{\circ} \mathrm{C}$.

\subsection{Scanning electron microscopy (SEM) and microanalysis}

The morphology of the elastomer film breakdown was investigated with an FEI Quanta 200E-SEM environmental scanning electron microscope, equipped with a field emission gun. The surface was visualized in low vacuum, using water vapors as auxiliary gas at a pressure of $150 \mathrm{~Pa}$. A mixture of secondary and back scattered electrons, generated by the sample surface, was detected with the large field detector for an incident electron beam of spot 3 accelerated to 10 $\mathrm{keV}$.

The elemental composition of the elastomer films was determined by energy dispersive X-rays (EDX) with an Oxford Instruments $80 \mathrm{~mm}^{2} \mathrm{X}$-Max silicon drift detector $\mathrm{Mn} \mathrm{K \alpha}$ resolution at $124 \mathrm{eV}$, also at low vacuum (150 Pa) with a 500 
$\mu \mathrm{m}$ pressure limiting aperture X-ray cone. The microanalysis data acquisition and quantification was performed with the Oxford Instruments Aztec program version 3.1.

\section{RESULTS AND DISCUSSION}

In the following results and discussions of the developed elastomers are presented. Firstly chemical and mechanical properties of the elastomers are presented before proceeding to a more detailed discussion on results from the electrical breakdown measurements.

\subsection{Chemical and mechanical analysis of developed elastomers}

Chloro propyl functional silicone elastomers, denoted Co-1 and Co-2, and the reference DMS-V31 elastomer were successfully prepared with almost identical molecular weight and details of the elastomers can be seen in Table 1 . The structure of the chloro propyl functional silicone elastomer is illustrated in Figure 1. The difference between Co- 1 and Co-2 is the different spacer lengths between the alkyl chloride-groups. Co-1 copolymer contains alkyl chloride-groups with $1200 \mathrm{~g} \mathrm{~mol}^{-1}$ dimethylsiloxane spacers between each group, and Co-2 copolymer contains alkyl chloride-groups with $580 \mathrm{~g} \mathrm{~mol}^{-1}$ dimethylsiloxane spacers between the functional groups. Co-2, with the shorter spacer, thus contains approximately double the amount of alkyl chloride functional groups than Co-1 prepared with the long spacer (at comparable copolymer lengths $)^{25}$.

Table 1. Details of prepared silicone elastomers.

\begin{tabular}{|c|c|c|}
\hline Name & Molecular weight between crosslinking sites $\mathbf{( g ~ m o l} \mathbf{~}^{-\mathbf{1}}$ ) & Concentration of chloro propyl groups (wt\%) \\
\hline DMS-V31 & 28,000 & 0 \\
\hline Co-1 & 29,000 & 2.0 \\
\hline Co-2 & 29,000 & 3.6 \\
\hline
\end{tabular}

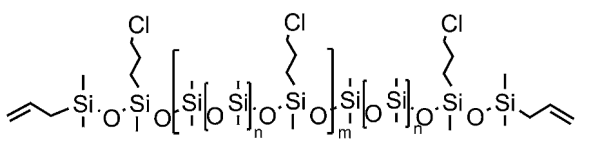
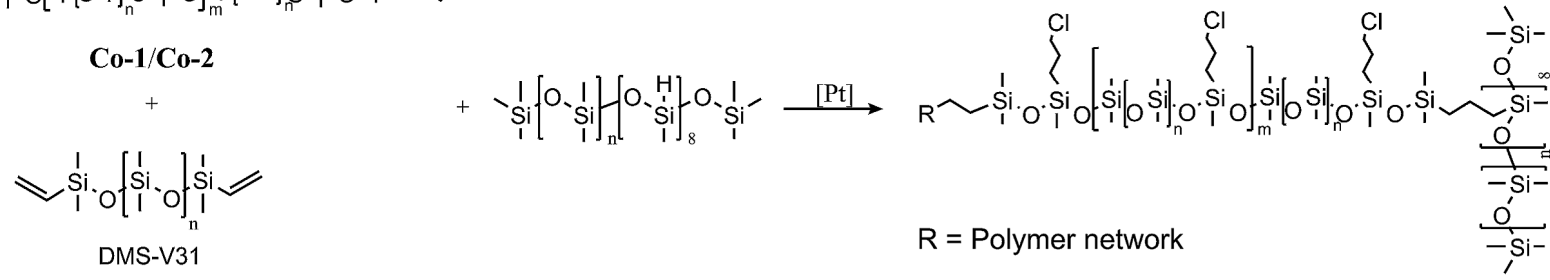

Figure 1. The structure of chloro propyl functional silicone elastomer.

Details of the properties of the elastomers are given in Table 2.

Table 2. Properties of prepared silicone elastomers. The thermogravimetric data is obtained from nitrogen atmosphere.

\begin{tabular}{|c|c|c|c|c|c|c|c|c|c|}
\hline Sample & $\begin{array}{c}T_{g} \\
\left({ }^{\circ} \mathbf{C}\right)\end{array}$ & $\begin{array}{l}T_{d 3 \%} \% \\
\left({ }^{\circ} \mathrm{C}\right)\end{array}$ & $\begin{array}{l}T_{\max } \\
\left({ }^{\circ} \mathrm{C}\right)\end{array}$ & $\begin{array}{c}\text { Residue } \\
\text { @900 }{ }^{\circ} \mathrm{C} \\
(\%)\end{array}$ & $\begin{array}{c}\mathbf{E}_{\text {breakdown }} \\
\left(\mathbf{V} \mu \mathbf{m}^{-1}\right)\end{array}$ & $\begin{array}{c}\text { Y@5\% } \\
\text { strain } \\
\text { (MPa) }\end{array}$ & $\begin{array}{c}\text { Tensile } \\
\text { strength } \\
\text { (MPa) }\end{array}$ & $\begin{array}{c}\text { Strain at } \\
\text { break } \\
(\%)\end{array}$ & $\begin{array}{c}\varepsilon_{\mathrm{r}} \\
(0.1 \mathrm{~Hz}\end{array}$ \\
\hline DMS-V31 & -117.2 & 414 & 670 & 58 & 82 & 1.81 & 6.08 & 374 & 3.3 \\
\hline Co-1 & -120.4 & 320 & 652 & 51 & 74 & 0.15 & 0.65 & 429 & 4.7 \\
\hline Co-2 & -116.8 & 323 & 665 & 56 & 94 & 0.52 & 1.27 & 314 & 5.1 \\
\hline
\end{tabular}


The resulting electro-mechanical properties of the Co-1 and Co-2 elastomers can be evaluated by comparison to the properties of the commercially available silicone elastomer film from Wacker Chemie AG with properties resembling the Elastosil RT625 (likewise from Wacker Chemie AG) by normalizing with the electro-mechanical properties of this elastomer.

The figure of merit for actuation is given $b y^{27}$ :

$$
\mathrm{F}_{\mathrm{om}}(\mathrm{DEA})=\frac{3 \varepsilon_{\mathrm{r}} \varepsilon_{0} \mathrm{E}_{\text {breakdown }}^{2}}{\mathrm{Y}}
$$

where $\mathrm{E}_{\text {breakdown }}$ is the electrical field at which electrical breakdown occurs, $\varepsilon_{\mathrm{r}}$ is the relative dielectric permittivity, $\varepsilon_{\mathrm{o}}$ is the permittivity of free space $\left(8.85 \times 10^{-12} \mathrm{~F} \mathrm{~m}^{-1}\right)$ and $\mathrm{Y}$ is the Young's modulus of the elastomer,

The figure of merit for energy generation is given $b y^{28}$ :

$$
\mathrm{F}_{\mathrm{om}}(\mathrm{DEG})=\frac{\varepsilon_{\mathrm{r}} \varepsilon_{0} \mathrm{E}_{\text {breakdown }}^{2}}{2 \phi}
$$

where $\Phi$ is the energy density function of the investigated elastomer. Due to lack of data for most silicone elastomers this is usually regarded as a constant and is thus ignored in relative comparisons ${ }^{17}$.

The properties of RT625 for the comparison are regarded as $\varepsilon_{\mathrm{r}} @ 0.1 \mathrm{~Hz}=3, \mathrm{Y} @ 5 \%$ strain $=1 \mathrm{MPa}$ and $\mathrm{E}_{\text {breakdown }}=80 \mathrm{~V}$ $\mu \mathrm{m}^{-1}{ }^{17}$ The normalized $\mathrm{F}_{\mathrm{om}}$ (DEA) of Co-1 and Co-2 elastomers with respect to the commercial reference become 8.9 and 4.5 , respectively. In other words, actuation at ultimate conditions of the developed elastomers is 9 and 4.5 times better than the commercial reference. The normalized $\mathrm{F}_{\text {om }}(\mathrm{DEG})$ of Co-1 and Co-2 elastomers are 1.3 and 2.3, respectively. Again, the normalized figures of merit provide a number for the improved energy harvesting at ultimate conditions. It is evident that the materials with chloro propyl functional silicone improved the dielectric elastomer performances for both actuation and energy generation applications. However, the main improvement was found for actuation due to the low Young's modulus of these materials. Usually a low Young's modulus causes low electrical breakdown strength ${ }^{17,29}$ but due to the voltage stabilization effect of the chloro propyl groups the developed elastomers do not follow this trend.

The thermogravimetric curves of the chloro propyl functional elastomers are shown in Figure 2. The thermal degradation temperatures for the samples prepared with alkyl chloride-functional copolymers decreased slightly compared to the reference film DMS-V31. However, the degradation temperatures remained similar to those of the reference elastomer. Therefore, as on overall observation, thermal degradation behavior was not altered significantly for the alkyl chloridefunctional elastomers compared to the pristine PDMS reference elastomer.

Obviously all synthesized elastomers are very stable with respect to temperature and are not fully degraded before a temperature of around $660^{\circ} \mathrm{C}$ is reached, as seen in Table 2. A reduction of $\mathrm{T}_{\mathrm{d} 3 \%}$ (the temperature at which $3 \%$ by mass is degraded) is observed when the amount of chloro propyl groups is increased indicating that the chloro propyl group - as expected - does not stabilize the silicone elastomer thermally.

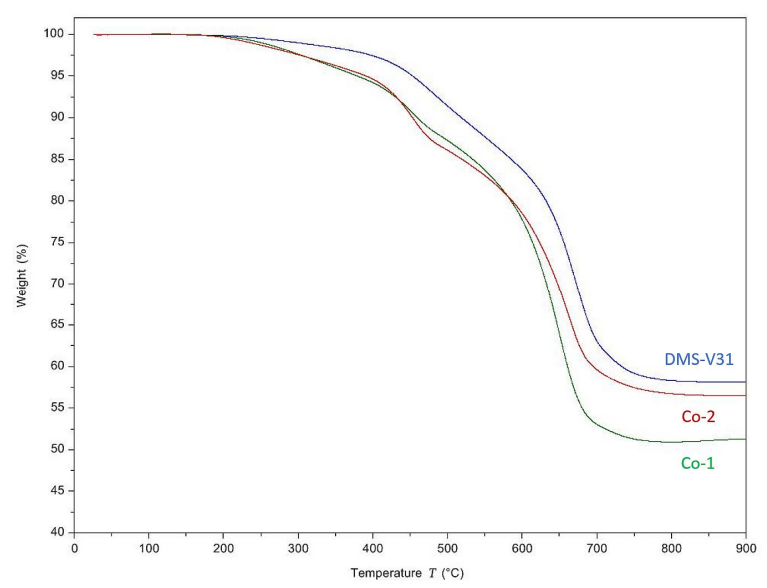

Figure 2. TGA of chloro propyl functional silicone elastomers. 


\subsection{Breakdown analysis}

Typical breakdown zones in silicone-based elastomers consist of a pin-hole with a surrounding region of solidification, both physically within and on top of the elastomer. This is illustrated in Figure 3. Three different breakdown zones (pinholes and surrounding area) of identical elastomers are shown. The main observation is that there is a large extent of solidified matter around the pin-hole as well as solidified "threads" spreading from the pinhole and outwards. These threads are unfortunate since they lead to stress inhomogeneities, which potentially may lead to tearing of the film if the breakdown experiment (or actuation) is performed in a non-zero stress configuration. The threads are not solely surface phenomena and span into the bulk of the material. Usually congruent patterns on both back and front side of the film are observed if the elastomer is inserted in the breakdown equipment in an unstretched configuration. This is of course sought in every single experiment but small stresses during the mounting are unavoidable.
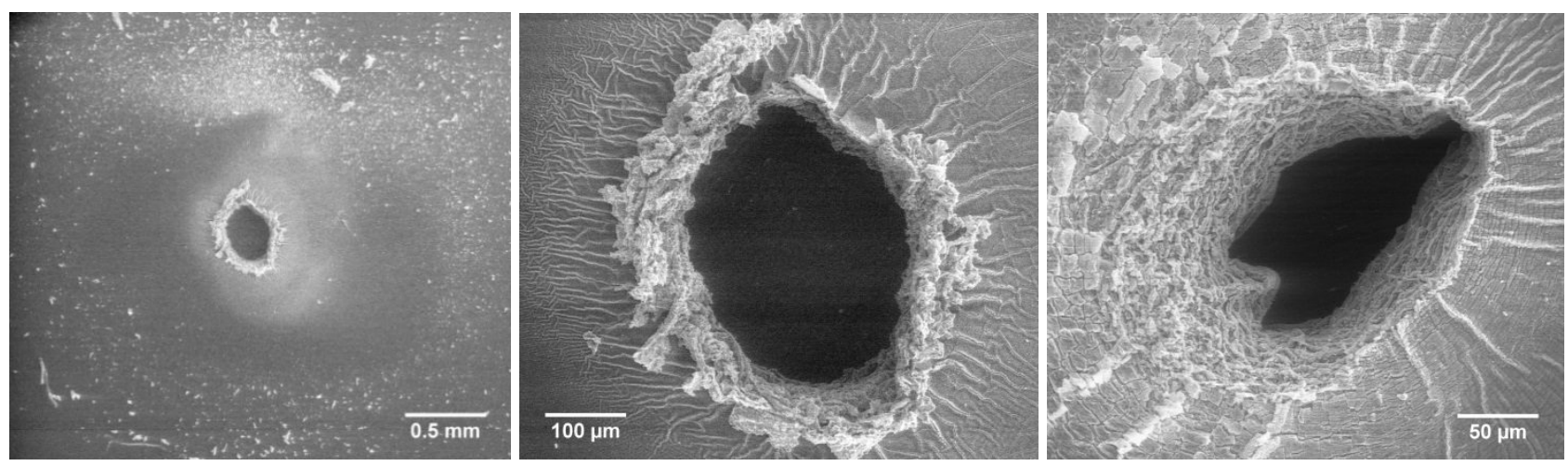

Figure 3. Illustration of common brittle failures after electrical breakdown. For all three breakdown zones there is a large extent of solidified matter around the pin-hole. The solidified "threads" spreading from the pinhole potentially lead to tearing of the film if the breakdown experiment (or actuation) is performed in a non-zero stress configuration.

For the synthesized elastomers varying degree of damage to the elastomer upon electrical breakdown was observed. Two different breakdown patterns were observed for the two almost identical crosslinked copolymers (the sole difference being doubling of chloro propyl concentration of Co-2 compared to Co-1). Examples of such patterns for all three synthesized elastomers are shown in Figure 4. The breakdown zones of the three different elastomers obviously do not look identical but the appearance is rather consistent within one elastomer.

The presence of large amounts of chloro propyl groups stabilizes the silicone elastomer electro-mechanically since the Co-2 elastomer has significantly larger electrical breakdown strength than the Co-1 elastomer (Table 2). This effect can partly be attributed to increased stiffness of the elastomer since Co-2 elastomer has a significantly larger Young's modulus than the Co-1 elastomer but with respect to the reference elastomer increased stiffness can not be the explanation and still the effect is significant. This gives a clear indication that a certain concentration of chloro propyl groups has a positive effect on the electrical properties, because the given concentration leads to a better morphology and/or electrical stabilization.

Obviously, Co-1 and Co-2 obviously decompose differently during the imposed electrical breakdown. The breakdown of Co-1 involves boiling of volatiles as can be seen in more detail in Figure 5. Co-2 elastomers possess an average electrical breakdown strength of $20 \mathrm{~V} \mathrm{\mu m}^{-1}$ higher than Co-1 elastomers and break down in what seems to be the more commonly observed pattern, namely by solidification of the elastomer around the pinhole and subsequent partial tearing due to the developed stress gradients around the solidified threads. The tearing process is a major challenge in silicone-based dielectric elastomer transducer products since the inherent tear strength of silicone elastomers is usually rather low ${ }^{30}$. 

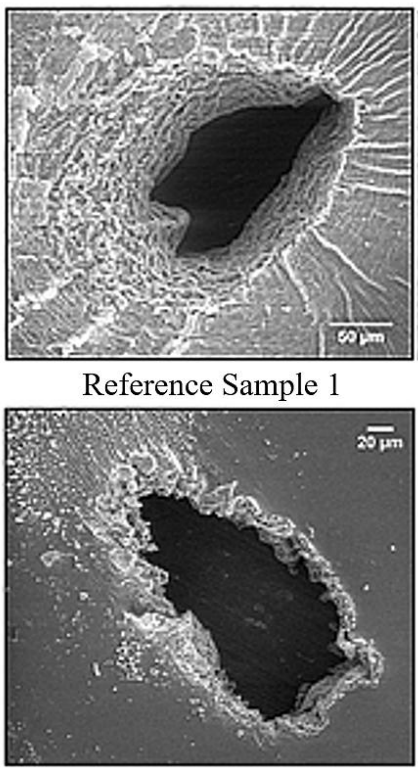

Co-1 Sample 1

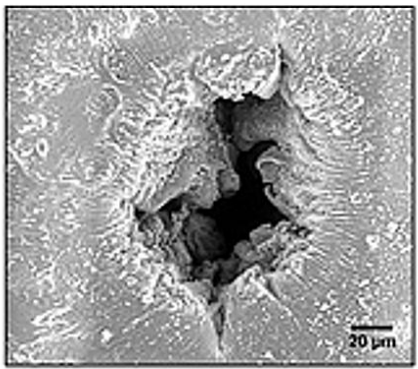

Co-2 Sample 1

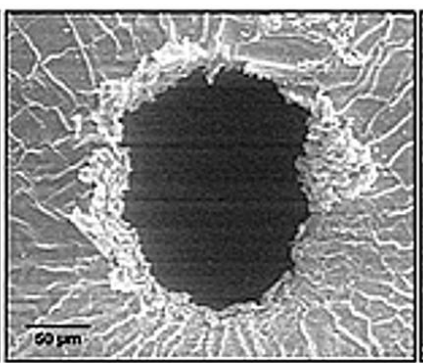

Reference Sample 2

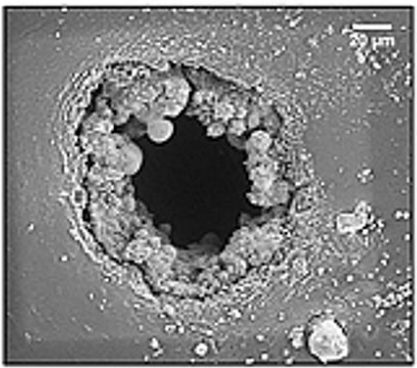

Co-1 Sample 2

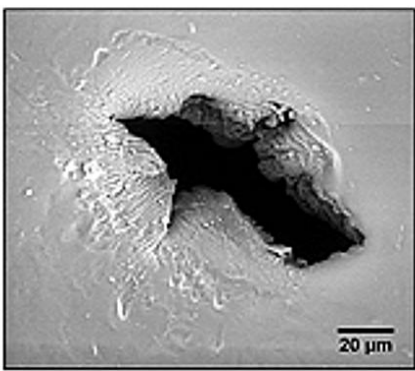

Co-2 Sample 2

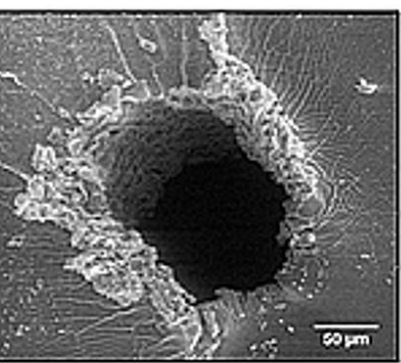

Reference Sample 3

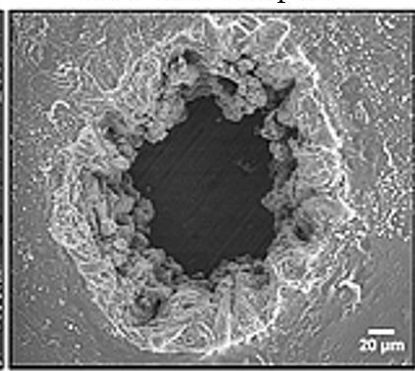

Co-1 Sample 3

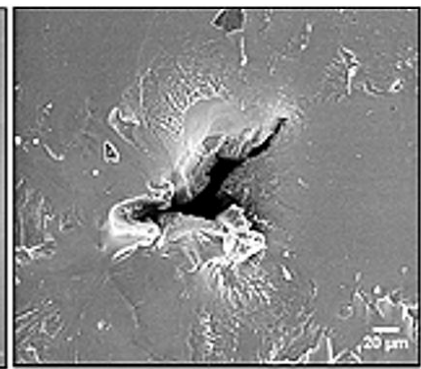

Co-2 Sample 3

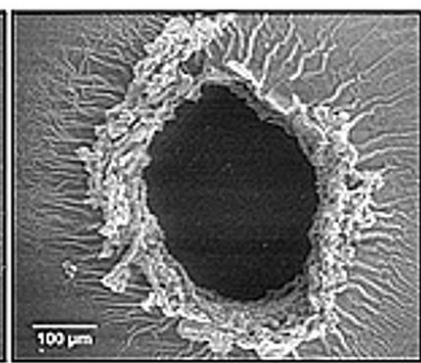

Reference Sample 4

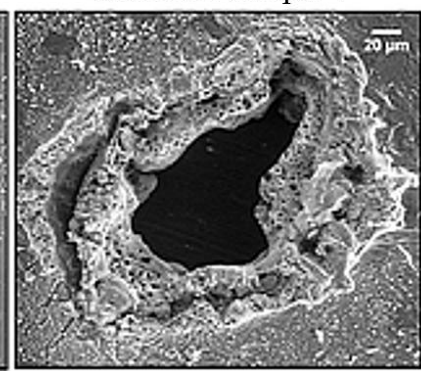

Co-1 Sample 4

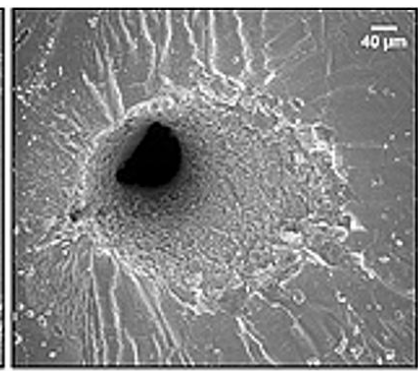

Co-2 Sample 4

Figure 4. Scanning electron micrographs of breakdown zones for (top) four reference samples, (middle) four Co-1 silicone elastomers, and (bottom) four Co-2 silicone elastomers. The black areas correspond to areas where the elastomer was completely removed during breakdown, i.e. pinholes. The white areas are solidified material with high silicium content. Not all scale bars are identical in order to show the most important features of the specific breakdown zones which vary dimensionally with narrowest width of around $40 \mu \mathrm{m}$ to largest width of around $400 \mu \mathrm{m}$.
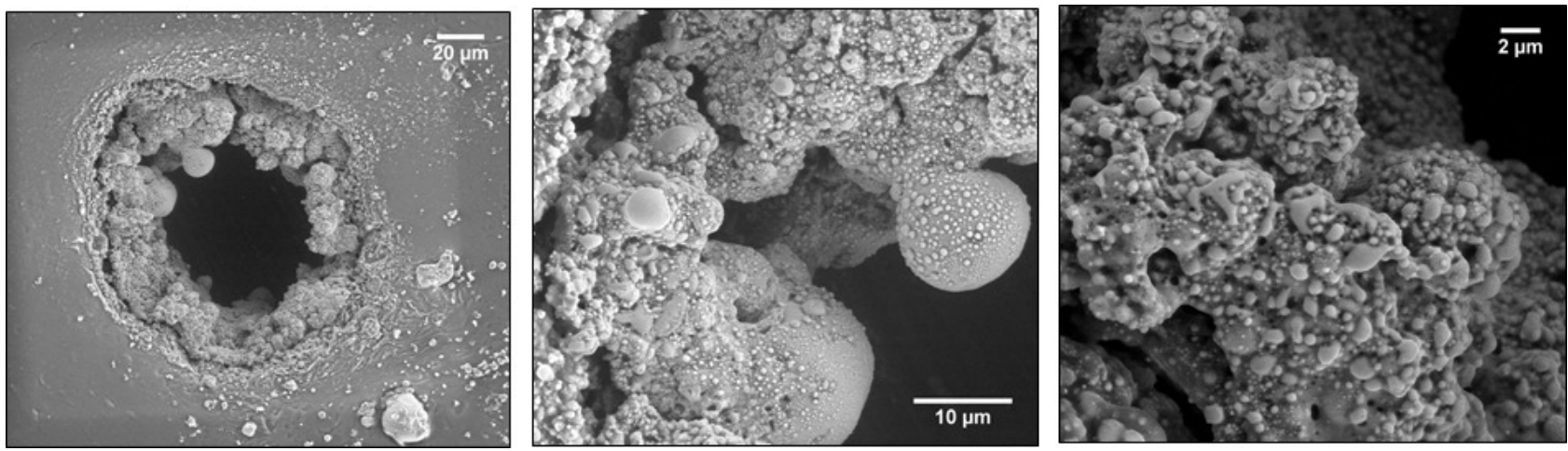

Figure 5. Illustration of boiling nature of the crosslinked copolymer Co-1 in different magnifications. Droplets of condensing degradation products are formed on the surface of the breakdown zone. Very little solidification is observed upon the introduced electrical breakdown in this elastomer, and most importantly, there is no solidified thread formation. 
In order to get a better idea of the involved breakdown phenomena, SEM/microanalysis was performed as well. The composition of the solidified zones for the Co-2 elastomer could not be detected due to lack of difference in elemental composition. But very interestingly, as is shown in Figure 6, it is first of all obvious that during the breakdown of Co-1 elastomer silicium-containing substances are burnt off and a chlorine-rich region remains. This is not the case for Co- 2 where the elemental composition is comparable throughout the breakdown zone. Obviously, the concentration of chloro propyl groups directly affects the electrical breakdown process. This observation paves the way toward molecular tailoring of more stable silicone elastomers where the main focus not necessarily is on the absolute value of the electrical breakdown strength but rather on a combined analysis of the electrical breakdown strength and the resulting tearing propagation upon electrical breakdown.

From thermal gravimetric analysis (TGA) of the investigated copolymers (shown in Figure 2), it is obvious that the breakdown process in terms of energies corresponds to the energies from a solely thermal degradation process of more than $500{ }^{\circ} \mathrm{C}$. Interestingly, one would expect $\mathrm{HCl}$ to form as a degradation byproduct (as for polyvinyl chloride) but this does not seem to be the case for any of the synthesized copolymer based elastomers (at least it takes place to less extent than the formation of volatile silicium-based degradation products). The formation of $\mathrm{HCl}$ would lead to an autodegradative process since a highly acidic environment is well-known to cause degradation of silicone polymers ${ }^{31}$. Within the current study it is not possible to couple the thermal behavior with the electrical breakdown process but as discussed previously the change in electrical breakdown behavior may also be a result of changed microscopic or even nanoscopic morphology. This is to be investigated further.
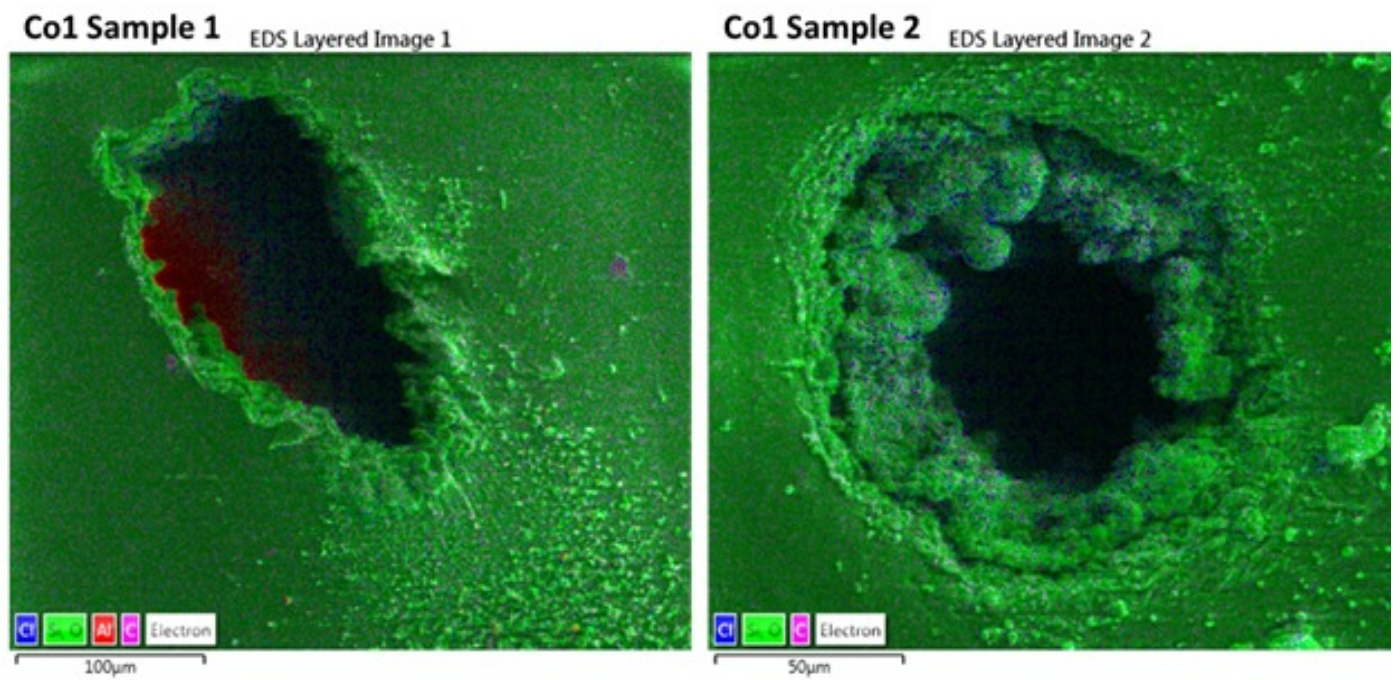

Figure 6. EDS mapping of the breakdown zones for the crosslinked copolymer Co-1. The material in the vicinity of the void contains excess of chlorine (blue color), which support the hypothesis that silicon-containing substances have been evaporated off. Aluminum traces arise from the aluminum stub underneath the pinholes, onto which the elastomer is mounted for the electron microscopy. EDS color legend: Chlorine-blue, Silicon and Oxygen-green, Carbon-pink and Aluminum-red.

Obviously the Co-1 elastomer breaks down prematurely in a static electrical breakdown experiment (compared to the two other elastomers) but on the other hand the breakdown zones are all without possible tear propagation from solidified threads. This can be explained by electrical energy being consumed in the evaporation process of the volatiles rather than in solidification. However, despite the premature breakdown the Co-1 elastomer may be a better candidate for dielectric elastomer products since the tendency of local (microscopic) electrical breakdown with subsequent macroscopic tearing will be reduced. 


\section{CONCLUSIONS}

It was shown the chemically very similar silicone elastomers broke down electrically in very different ways. These observations emphasize that the modification of the silicone backbone may open up for completely new possibilities for stabilizing the silicone elastomer electrically. In order to tailor the elastomers, more knowledge is needed but the results of these crosslinked copolymers pave the first path towards a better understanding of the complex connection between electrical stability and thermal stability and morphology. Minor changes in the polymer backbone structure result in changes in electrical breakdown patterns and understanding why is crucial for enabling design for extraordinarily stable elastomers and thus ultimately reliable dielectric elastomer based products.

\section{REFERENCES}

[1] Pelrine, R., Kornbluh, R., Pei, Q., Pelrine, J. J. R., "High-speed electrically actuated elastomers with strain greater than 100\%," Science 287(5454), 836-839 (2000).

[2] Zhao, X., Suo, Z., "Theory of dielectric elastomers capable of giant deformation of actuation," Physical Review Letters 104(17), 178302 (2010).

[3] Michel, S., Zhang, X. Q., Wissler, M., Löwe, C., Kovacs, G., "A comparison between silicone and acrylic elastomers as dielectric materials in electroactive polymer actuators," Polymer International 59(3), 391-399 (2010).

[4] Rosset, S., Araromi, S., Schlatter, S., Shea, H., "Fabrication process of silicone-based dielectric elastomer actuators," Journal of Visualized Experiments 2016(108), 53423 (2016).

[5] Brochu, P., Pei, Q., "Advances in dielectric elastomers for actuators and artificial muscles," Macromolecular Rapid Communications 31(1), 10-36 (2010).

[6] Ştiubianu, G., Soroceanu, A., Varganici, C.-D., Tugui, C., Cazacu, M., "Dielectric elastomers based on silicones filled with transitional metal complexes," Composites Part B: Engineering 93, 236-243 (2016).

[7] Yu, L., Skov, A. L., "Silicone rubbers for dielectric elastomers with improved dielectric and mechanical properties as a result of substituting silica with titanium dioxide," International Journal of Smart and Nano Materials 6(4), 268-289 (2016).

[8] Gallone, G., Carpi, F., Rossi, D. D., Levita, G., Marchetti, A., "Dielectric constant enhancement in a silicone elastomer filled with lead magnesium niobate-lead titanate," Materials Science and Engineering: C 27(1), 110116 (2007).

[9] Mazurek, P., Yu, L., Gerhard, R., Wirges, W., Skov, A. L., "Glycerol as high-permittivity liquid filler in dielectric silicone elastomers," Journal of Applied Polymer Science 133(43), 44153 (2016).

[10] Mazurek, P., Hvilsted, S., Skov, A. L., "Green silicone elastomer obtained from a counterintuitively stable mixture of glycerol and PDMS," Polymer 87, 1-7 (2016).

[11] Madsen, F. B., Yu, L., Daugaard, A. E., Hvilsted, S., Skov, A. L., "Silicone elastomers with high dielectric permittivity and high dielectric breakdown strength based on dipolar copolymers," Polymer 55(24), 6212-6219 (2014).

[12] Madsen, F. B., Daugaard, A. E., Hvilsted, S., Benslimane, M. Y., Skov, A. L., "Dipolar cross-linkers for PDMS networks with enhanced dielectric permittivity and low dielectric loss," Smart Materials and Structures 22(10), 104002 (2013).

[13] Tugui, C., Vlad, S., Iacob, M., Varganici, C. D., Pricop, L., Cazacu, M., "Interpenetrating poly(urethane-urea)polydimethylsiloxane networks designed as active elements in electromechanical transducers," Polymer Chemistry 7, 2709-2719 (2016).

[14] Racles, C., Alexandru, M., Bele, A., Musteata, V. E., Cazacua, M., Opris, D. M., "Chemical modification of polysiloxanes with polar pendant groups by co-hydrosilylation," RSC Advances 4, 37620-37628 (2014).

[15] A. Razak, A. H., Szabo, P., Skov, A. L., "Enhancement of dielectric permittivity by incorporating PDMS-PEG multiblock copolymers in silicone elastomers," RSC Advances 5(65), 53054-53062 (2015).

[16] A. Razak, A. H., Skov, A. L., "Silicone elastomers with covalently incorporated aromatic voltage stabilisers," RSC Advances 7(1), 468-477 (2017).

[17] Madsen, F. B., Daugaard, A. E., Hvilsted, S., Skov, A. L., "The current state of silicone-based dielectric elastomer transducers," Macromolecular Rapid Communications 37(5), 378-413 (2016). 
[18] Gatti, D., Haus, H., Matysek, M., Frohnapfel, B., Tropea, C., Schlaak, H. F., "The dielectric breakdown limit of silicone dielectric elastomer actuators," Applied Physics Letters 104(5), 052905 (2014).

[19] Troels, A., Kogler, A., Baumgartner, R., Kaltseis, R., Keplinger, C., Schwoediauer, R., Graz, I., Bauer, S., "Stretch dependence of the electrical breakdown strength and dielectric constant of dielectric elastomers," Smart Materials and Structures 22(10), 104012 (2013).

[20] Goswami, K., Daugaard, A. E., Skov, A. L., "Dielectric properties of ultraviolet cured poly(dimethyl siloxane) sub-percolative composites containing percolative amounts of multi-walled carbon nanotubes," RSC Advances 5, 12792-12799 (2015).

[21] Kussmaul, B., Risse, S., Kofod, G., Waché, R., Wegener, M., McCarthy, D. N., Krüger, H., Gerhard, R., "Enhancement of dielectric permittivity and electromechanical response in silicone elastomers: molecular grafting of organic dipoles to the macromolecular network," Advanced Functional Materials 21(23), 4589-4594 (2011).

[22] Englund, V., Huuva, R., Gubanski, S. M., Hjertberg, T., "High efficiency voltage stabilizers for XLPE cable insulation," Polymer Degradation and Stability 94, 823-833 (2009).

[23] Yamano, Y., "Roles of polycyclic compounds in increasing breakdown strength of LDPE film," IEEE Transactions on Dielectrics and Electrical Insulation 13(4), 773-781 (2006).

[24] Yamano, Y., Endoh, H., "Increase in breakdown strength of PE film by additives of azocompounds," IEEE Transactions on Dielectrics and Electrical Insulation 5(2), 270-275 (1998).

[25] Madsen, F. B., Yu, L., Daugaard, A. E., Hvilsted, S., Skov, A. L., "A new soft dielectric silicone elastomer matrix with high mechanical integrity and low losses," RSC Advances 5(14), 10254-10259 (2015).

[26] Madsen, F. B., Yu, L., Mazurek, P., Skov, A. L., "A simple method for reducing inevitable dielectric loss in high-permittivity dielectric elastomers," Smart Materials and Structures 25, 075018 (2016).

[27] Sommer-Larsen, P., Larsen, A. L., "Materials for dielectric elastomer actuators," SPIE Proceeding 5385, 68-77 (2004).

[28] McKay, T. G., Calius, E., Anderson, I. A., "Dielectric constant of 3M VHB: a parameter in dispute," SPIE Proceeding 7287, 72870P-1-72870P-10 (2009).

[29] Carpi, F., Gallone, G., Galantini, F., Rossi, D. D., "Silicone-poly(hexylthiophene) blends as elastomers with enhanced electromechanical transduction properties," Advanced Functional Materials 18, 235-241 (2008).

[30] Vudayagiri, S., Junker, M. D., Skov, A. L., "Factors affecting the surface and release properties of thin polydimethylsiloxane films," Polymer Journal 45, 871-878 (2013).

[31]Feng, J., Zhang, Q., Tu, Z., Tu, W., Wan, Z., Pan, M., Zhang, H., "Degradation of silicone rubbers with different hardness in various aqueous solutions," Polymer Degradation and Stability 109, 122-128 (2014). 